\title{
Urinary Monocyte Chemoattractant Protein-1 (MCP-1) in Renal Transplant Recipients: Implications in Proteinuric Patients
}

\author{
Alieu B. Amara ${ }^{1,2}$, Liliana Shalamanova ${ }^{1}$, Asheesh Sharma ${ }^{1}$, Alan Shenkin ${ }^{2}$, Ali Bakran ${ }^{3}$, \\ Ajay K. Sharma ${ }^{3}$, Abdul Hammad ${ }^{3}$ and Rana Rustom ${ }^{1,3, *}$
}

${ }^{l}$ School of Clinical Sciences, Division of Metabolic and Cellular Medicine, University of Liverpool, Liverpool L69 3GA, United Kingdom; ${ }^{2}$ School of Clinical Sciences, Division of Clinical Chemistry, University of Liverpool, Liverpool L69 3GA, United Kingdom and ${ }^{3}$ Sir Peter Medawar Unit, Duncan Building, Royal Liverpool University Hospital, Liverpool L7 8XP, United Kingdom

\begin{abstract}
Background: After the first year of transplantation chronic allograft nephropathy is the most important cause of renal graft loss and hypertension and proteinuria occur commonly. In native nephropathies, proteinuria and progression to renal failure are linked and renal tubulo-interstitial fibrosis determines prognosis. Monocyte chemoattractant protein-1 (MCP-1) is a powerful chemokine promoting tubulo-interstitial fibrosis but data are limited in a transplant context. Hence this observational cross-sectional study.

Methods: The MAP, 24h urinary creatinine clearance, proteinuria and MCP-1 were measured in 81 renal transplant patients (43 with chronic allograft nephropathy). Most patients were on calcineurin-inhibitor based immunosuppression. Regression analysis was applied and comparisons made with 64 patients with native nephropathies and comparable function.

Results: One fifth (18/81) of all renal transplant patients had less than optimally controlled hypertension. Proteinuria was heaviest in non-transplanted patients (average $3.0 \mathrm{~g} / 24 \mathrm{~h}, 0.1-12.2)$ and the ciclosporin-treated transplant patients $(1.2$ $\mathrm{g} / 24 \mathrm{~h}, 0.02-6.4)$. Proteinuria and MCP-1 were positively correlated in all patients ( $0.54, \mathrm{p}<0.0001)$ and $\mathrm{r} 0.84, \mathrm{p}<0.0001$ in 19 transplant patients receiving angiotensin-converting enzyme inhibitors. MCP-1 levels were highest in non-transplant and ciclosporin-treated patients; geometric mean (SE), 412.4(1.16) and 314.5(1.21) pg/24h respectively. MCP-1 levels were unrelated to age, MAP, creatinine clearance, or blood ciclosporin or tacrolimus levels.
\end{abstract}

Conclusions: Urinary MCP-1 may be a useful non-invasive marker of chronic graft dysfunction in transplant patients facilitating monitoring of progression and response to treatment even in proteinuric patients.

\section{INTRODUCTION}

After the first year of transplantation chronic allograft nephropathy is the major cause of renal transplant failure [1]. Chronic allograft nephropathy is characterised by chronic inflammation, fibrosis and tubular atrophy. Although the pathogenesis of chronic allograft nephropathy remains unclear, proteinuria, hypertension and proximal tubular damage are frequently present. This pattern is similar to that seen in progressive native nephropathies where proteinuria and progression to renal failure are linked [2-4]. Additionally, the extent of tubulo-interstitial fibrosis determines the rate of decline of renal function and prognosis [5-6].

We have previously shown in proteinuric patients with chronic allograft nephropathy increased proximal tubular cell (PTC) catabolism of the polypeptide Aprotinin to be linked with increased markers of PTC injury/hyperfunction [7-8]. The proximal tubules in chronically damaged transplanted kidneys seemed to behave in a manner similar to diseased kidneys in their native setting with additional tubular injury from immunosuppression using calcineurin inhibitors [8].

*Address correspondence to this author at the School of Clinical Sciences, Division of Metabolic and Cellular Medicine, Duncan Building, Liverpool L69 3GA, United Kingdom; Tel: +44 151706 4663; Fax: +44 151706 5802; E-mail: rana.rustom@liverpool.ac.uk
Monocyte chemoattractant protein-1 (MCP-1) is one of the most powerful chemoattractants of macrophages/monocytes and T lymphocytes [9]. MCP-1 is produced locally by PTCs and induces a series of inflammatory events, leading to secretion of other cytokines, activation of transcription factors and up-regulation of growth factors, especially the profibrogenic transforming growth factor (TGF- $\beta 1$ ) promoting tubulo-interstitial fibrosis [9-12].

Increased urinary MCP-1 levels, as a marker of inflammation, have been previously described in patients with different glomerulonephritides where levels significantly correlated with proteinuria [13-16] and with the severity of tubulo-interstitial fibrosis $[14,15]$. However, MCP-1 data remains very limited in the context of renal transplantation and especially in proteinuric patients with chronic allograft nephropathy. Grandaliano et al. [17] linked increased urinary MCP-1 levels in renal recipients with acute allograft rejection. In this observational study, we redress this imbalance by providing data on $24 \mathrm{~h}$ urinary $\mathrm{MCP}-1$ in renal transplant patients more than 6 months (most after one year) after transplantation (including those with chronic allograft nephropathy). Using regression analysis, we link urinary MCP-1 with proteinuria and discuss the clinical implications. Urine specimens from proteinuric patients with different native nephropathies (and similar renal function as in the transplant recipients) and from normal subjects were also examined. 


\section{PATIENTS, MATERIALS AND METHODS}

Since urinary MCP-1 data in proteinuric transplant patients after the first 6 months of transplantation were unavailable the design of this observational study was guided by our previously published data on urinary $\mathrm{N}$-acetyl $\beta, \mathrm{D}$ glucosaminidase (NAG) in patients with diseased native kidneys [18] and transplanted patients with chronic allograft nephropathy [8]. Patients were recruited from a single outpatient clinic over a twenty month period, providing they had evidence of $>0.5 \mathrm{~g} / 24 \mathrm{~h}$ proteinuria on at least three previous visits in the preceding 6 months and were $\geq 6$ months (most after one year) post-transplantation (patients attending this clinic routinely have $24 \mathrm{~h}$ urine measurements for creatinine clearance and proteinuria and are well trained in this procedure). Additionally, all willing patients seen with biopsyproven chronic allograft nephropathy during the period of study were also included. All patients on calcineurininhibitor treatment had trough level measurements for ciclosporin or tacrolimus. Patients with evidence of calcineurin inhibitor toxicity were excluded.

Urine specimens (24h) were thus collected from 81 outpatients who had undergone transplantation on average 8.2 years previously (range $0.5-26.0$ years; 5 patients between 0.5-1 year, 21 patients transplanted between 1-2 years; 48 patients 2-20 years, 6 patients 20-23 years; 1 patient at 26 years).

Urine specimens from 64 nontransplant renal outpatients (attending a single outpatient nephrology clinic) with comparable renal function to the transplant patients were also studied for MCP-1 and creatinine clearance. These patients included glomerulonephritis $(n=41)$ hypertension $(n=2)$, diabetes $(n=6)$, polycystic kidney disease $(n=5)$, chronic pyelonephritis or congenital renal dysplasia $(n=8)$ and other $(\mathrm{n}=2)$.

Urine samples from 17 healthy volunteers were also investigated. The study had approval from the Local Ethical Committee of the Royal Liverpool University Hospital.

Urinary MCP-1 (24h) was measured using a Quantikine ${ }^{\circledR}$ Human MCP-1 enzyme linked immunosorbent assay kit (R\&D Systems, Abingdon, UK). 24h proteinuria and other urinary biochemistries were measured by standard techniques as previously using Wako Autokit Micro TP Kit (Alpha Laboratories, Hampshire, UK) on a Hitachi 747 Automatic Analyser (Hitachi, Lewes, UK) [8].

\section{Data Analyses}

SigmaPlot for Windows (SPSS Inc., Chicago, IL) and StatsDirect software (StatsDirect Ltd., Cheshire, United Kingdom) were used to analyze the data and results were expressed as arithmetic means \pm SE. Statistical analyses on skewed non-parametric data were performed after logarithmic transformation and expressed as geometric means (SE). Student's $t$ test with Bonferroni's modification was also used. Linear regressions were calculated after log transformation of the data.

\section{RESULTS}

Clinical and demographic data for all donors and patients are listed in Tables $\mathbf{1}$ and $\mathbf{2}$. All patients had a creatinine clearance of at least $15 \mathrm{ml} / \mathrm{min}$. Forty four patients were taking ciclosporin-based immunosuppression, 18 were on tacrolimus-based treatment, and 18 were on other agents (prednisolone with azathioprine or mycophenolate mofetil, 1 patient on sirolimus). Forty three patients had biopsy-proven chronic allograft nephropathy; in the majority of patients (34) tubulo-interstitial fibrosis was mild-moderate (and severe in 9).

Most patients were taking at least one hypotensive agent for blood pressure control ( $\beta$-blockers, vasodilators, or calcium-channel blockers with or without diuretics). Additionally, 18 patients were on angiotensin-converting enzyme inhibitor (ACE-i) agents and 1 on an angiotensin II receptor blocker; of these all but two were on calcineurin-inhibitor treatment; 9 on ciclosporin- and 8 on tacrolimus-based immunosuppression. The mean arterial blood pressures (MAP) from blood pressure readings taken sitting and standing were calculated as the diastolic $+1 / 3$ (systolic-diastolic) $\mathrm{mm} \mathrm{Hg}$.

Ciclosporin dosages averaged $204 \pm 16 \mathrm{mg} /$ day (range, $50-500 \mathrm{mg} /$ day) $(3.1 \pm 0.2 \mathrm{mg} / \mathrm{kg} /$ day; $0.8-6.2 \mathrm{mg} / \mathrm{kg} / \mathrm{day})$. Twelve-hour trough ciclosporin levels were $148 \pm 11.7 \mu \mathrm{g} / \mathrm{L}$ (85-285 $\mu \mathrm{g} / \mathrm{L}$; HPLC equivalents). Tacrolimus dosages av-

Table 1. Characteristics of Donors and Renal Transplant Recipients. Results are Expressed as Mean \pm SE (Range)

\begin{tabular}{|c|c|c|c|}
\hline Donor & & $\begin{array}{c}\text { Cadaveric No }(\%) \\
\text { Live Related No }(\%) \\
\text { Sex }(\mathrm{M} / \mathrm{F}) \\
\text { Age }(\mathrm{y})\end{array}$ & $\begin{array}{c}63(77) \\
19(23) \\
34 / 41 \\
48.5 \pm 3.0(13-69)\end{array}$ \\
\hline Recipient & & $\begin{array}{l}\text { Sex }(M / F) \\
\text { Age }(y r)\end{array}$ & $\begin{array}{c}63 / 18 \\
52.8 \pm 1.5(22-80)\end{array}$ \\
\hline & Native renal pathology (\%) & $\begin{array}{c}\text { Glomerulonephritis, Diabetic Nephropathy, Nephrosclerosis } \\
\text { Interstitial disease/ Chronic Pyelonephritis } \\
\text { Adult Polycystic Kidney Disease } \\
\text { Unknown/other }\end{array}$ & $\begin{array}{l}71.1 \\
10.6 \\
5.3 \\
13.0\end{array}$ \\
\hline & Transplant function & $\begin{array}{l}\text { Delayed Graft Function (\%) } \\
\text { Episodes of Acute Rejection }\end{array}$ & $\begin{array}{c}24.4 \\
0.8 \pm 0.09(0-3)\end{array}$ \\
\hline
\end{tabular}


Table 2. Patient Characteristics; Mean Arterial Pressure (MAP), Creatinine Clearance (CrCl), 24-h Urinary Protein (UProt) and MCP-1 in Transplant Patients (TP), Non Transplant Patients with Native Kidney Disease (Non TP) and Healthy Volunteers. Age and MAP are Expressed as Mean \pm SE, Whereas CrCl, UProt and MCP-1 as Geometric Mean (SE) (Range)

\begin{tabular}{|c|c|c|c|c|c|c|c|c|}
\hline All TP Patients & 81 & $63 / 18$ & $\begin{array}{c}52.8 \pm 1.5^{\mathrm{a}} \\
(22-80)\end{array}$ & $\begin{array}{c}8.2 \pm 0.7 \\
(0.5-26.0)\end{array}$ & $\begin{array}{l}98.5 \pm 1.4^{\mathrm{a}} \\
(70-143)\end{array}$ & $\begin{array}{c}34.3(1.08) \\
(15-98)\end{array}$ & $\begin{array}{l}0.59(1.17)^{\mathrm{c}} \\
(0.02-6.63)\end{array}$ & $\begin{array}{c}252.3(1.14)^{a, b} \\
(21-3855)\end{array}$ \\
\hline Non TP Patients & 64 & $40 / 24$ & $\begin{array}{c}52.7 \pm 1.9^{\mathrm{a}} \\
(22-86)\end{array}$ & - & $\begin{array}{c}102.7 \pm 1.1^{\mathrm{a}} \\
(70-133)\end{array}$ & $\begin{array}{c}40.1(1.08) \\
(15-112)\end{array}$ & $\begin{array}{c}2.04(1.13) \\
(0.11-12.24)\end{array}$ & $\begin{array}{c}412.4(1.16)^{\mathrm{a}} \\
(16-3538)\end{array}$ \\
\hline Volunteers & 17 & $7 / 10$ & $\begin{array}{c}37.5 \pm 2.0 \\
(28-54)\end{array}$ & - & $\begin{array}{l}86.5 \pm 2.5 \\
(74-102)\end{array}$ & - & $\begin{array}{l}0.05(0.02) \\
(0.04-0.06)\end{array}$ & $\begin{array}{c}139.9(1.27) \\
(9-577)\end{array}$ \\
\hline
\end{tabular}

${ }^{\mathrm{a} \& \mathrm{~b}} \mathrm{p}<0.001 \& 0.01$ compared with Volunteers; ${ }^{\mathrm{b}} \mathrm{p}<0.01,{ }^{\mathrm{c}} \mathrm{p}<0.0001$ compared with Non TP.

eraged $6.2 \pm 1.1 \mathrm{mg} /$ day $(0.5-18 \mathrm{mg} /$ day $)(0.11 \pm 0.02 \mathrm{mg} / \mathrm{kg} /$ day; $0.06-0.17 \mathrm{mg} / \mathrm{kg} /$ day). Twelve-hour tacrolimus levels were $8.5 \pm 1.0 \mu \mathrm{g} / \mathrm{L},(4.4-12.7 \mu \mathrm{g} / \mathrm{L})$.

Patients not on calcineurin inhibitors had been transplanted the longest (14y, 1.0-26y), and those on tacrolimusbased immunosuppression for the shortest periods $(3.6,1.0$ $13 \mathrm{y}$ cf. $6.8,1.0-18 \mathrm{y}, \mathrm{p}<0.05$ for patients on ciclosporin-based regimens). The MAP in the patients was, as expected, higher than in the volunteers. Approximately one fifth (18/81) of all patients had less than optimally controlled hypertension. The MAP was surprisingly highest in the tacrolimus-treated and patients with native nephropathies (103.4 $\pm 3.1,90-143$ $\mathrm{mmHg}$ and $102.7 \pm 1.1,70-133 \mathrm{mmHg}$ respectively). The MAP was lowest in ciclosporin-treated (96.8 $\pm 1.8,73-132$ $\mathrm{mmHg}$ ) and transplant patients on non-calcineurin regimens (97.8 $\pm 3.6,70-135 \mathrm{mmHg})$. Renal function was comparable in all patients averaging at $39.0 \mathrm{ml} / \mathrm{min}$ in the transplanted patients (15-98) and $48.0 \mathrm{ml} / \mathrm{min}$ (15-112) in the nontransplanted patients (Table 2 , data presented as geometric mean(SE) and range). The best renal function was found in patients on non-calcineurin inhibitor regimens (creatinine clearance, $51.7 \mathrm{ml} / \mathrm{min}, 15-98)$.

In the transplant patients, proteinuria averaged at 1.3 $\mathrm{g} / 24 \mathrm{~h}(0.02-6.6) ; 43$ patients had proteinuria $<0.5 \mathrm{~g} / 24 \mathrm{~h}$, the rest $>0.5 \mathrm{~g}$ (with 32 patients $>1 \mathrm{~g} / 24 \mathrm{~h}$ ), this distribution of proteinuria was also similar in patients with biopsy proven chronic allograft nephropathy. In Table 2 proteinuria data presented as geometric mean (SE) range. Proteinuria was lowest in the non-calcineurin inhibitor-treated patients (averaging $0.8 \mathrm{~g} / 24 \mathrm{~h}, 0.02-3.0)$ and highest in the ciclosporintreated patients (averaging $1.2 \mathrm{~g} / 24 \mathrm{~h}, 0.02-6.4 \mathrm{~g} / 24 \mathrm{~h}$ ). Proteinuria in patients on tacrolimus-based immunosuppression averaged at $1.0 \mathrm{~g} / 24 \mathrm{~h}(0.1-4.2)$. Transplant duration was unrelated to creatinine clearance or proteinuria. In patients with native diseased kidneys proteinuria was significantly greater than in the transplanted population and averaged at $3.0 \mathrm{~g} / 24 \mathrm{~h}$ (0.1-12.2) (6 patients had $<0.5 \mathrm{~g} / 24 \mathrm{~h}$ and the rest $>0.5 \mathrm{~g} / 24 \mathrm{~h}$, with 49 patients $>1 \mathrm{~g} / 24 \mathrm{~h}$ ), Table 2 .

Urinary MCP-1 and proteinuria were positively correlated in all patients (Fig. 1). This was strongest in the transplant patients receiving ACE-i therapy (Fig. 2); 12 patients had proteinuria $<0.5 \mathrm{~g} /$ day and 7 with proteinuria $>1 \mathrm{~g} / \mathrm{d}$ ). The results in patients with biopsy proven chronic allograft nephropathy are shown in Fig. (3). There were no significant differences in the regression coefficients of $\log$ urinary MCP1-log urinary protein plots between transplant and nontransplant patients. Urinary MCP-1 levels were unrelated to age, transplant duration, MAP, creatinine clearance, or blood ciclosporin or tacrolimus levels.

The 24h urinary MCP-1 levels were significantly higher in transplanted and non-transplanted patients compared with healthy volunteers (Table 2). The highest MCP-1 levels were in non-transplant patients with significantly greater proteinuria. Among transplanted patients, those on ciclosporin-based immunosuppression (with heavier proteinuria) had higher levels of MCP-1 compared with other patients [geometric mean (SE) range, 314.5(1.21), 42-3855 pg/24h cf. 165.3 (1.31), 21-1423 pg/24h in tacrolimus-treated patients and 166.8(1.21), 30-941 pg/24h in patients on non-calcineurin inhibitor regimens, $\mathrm{p}<0.05]$.

\section{DISCUSSION}

Proteinuria is an important clinical tool in renal transplantation and often predates any decline in renal graft function in patients with progressive chronic allograft nephropathy. Serial measurements in individual patients are invaluable in our experience in allowing early diagnosis, intervention and monitoring of both progression and response to treatment. The degree of tubulo-interstitial injury determines prognosis in native and transplanted kidneys $[1,8,18]$. Urinary markers of inflammation may thus be helpful additional tools but can be difficult to interpret in proteinuric conditions because of possible varied contribution in urine from that filtered from plasma $[8,18]$. Data on urinary MCP-1 in a transplant context are limited and even less is known in proteinuric patients. The results from this observational crosssectional clinical study reports, to our knowledge, for the first time the relationship between urinary MCP-1 and proteinuria in renal transplant patients from 6 months to many years post-transplantation and in a relatively large number of patients.

Patients with renal transplants had lower urinary MCP-1 activity than those with native diseased kidneys for comparable degrees of renal impairment. This can be explained by glomerular disease and the heavier proteinuria arising from two kidneys rather than one transplanted organ. The intercept 


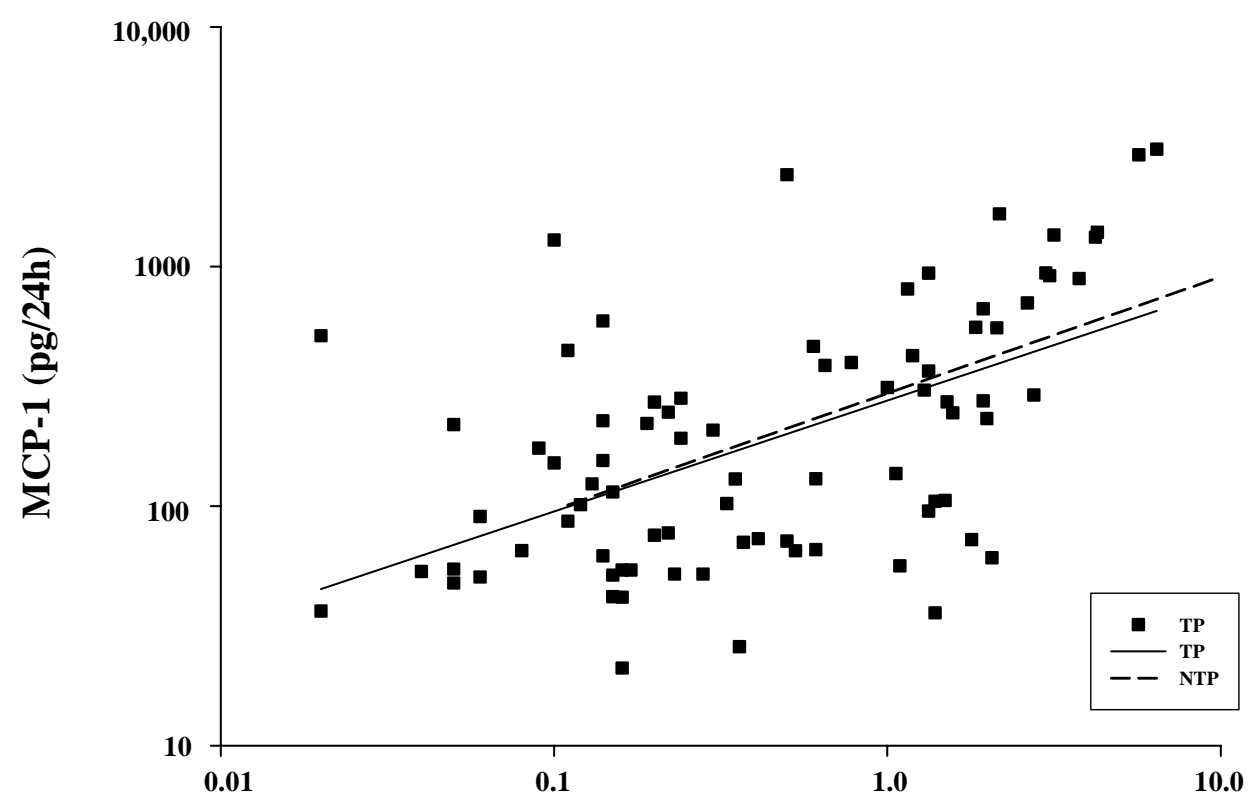

Urinary Protein $(\mathrm{g} / \mathbf{2 4 h})$

Fig. (1). Correlations between 24-hr proteinuria (UProt) and total urinary MCP-1 activity (log-log plots) in all patients. Data for all transplant patients (TP) ( - ) are shown with the regression plots for TP (solid line) y $=2.44+0.46 \mathrm{x} ; \mathrm{r}=0.54, \mathrm{p}<0.0001$ and only the regression (dashed line) for non-transplant patients (Non TP) $y=2.247+0.49 x ; r=0.42, p<0.0001$. The individual values in the non-transplant patients have been omitted for clarity.

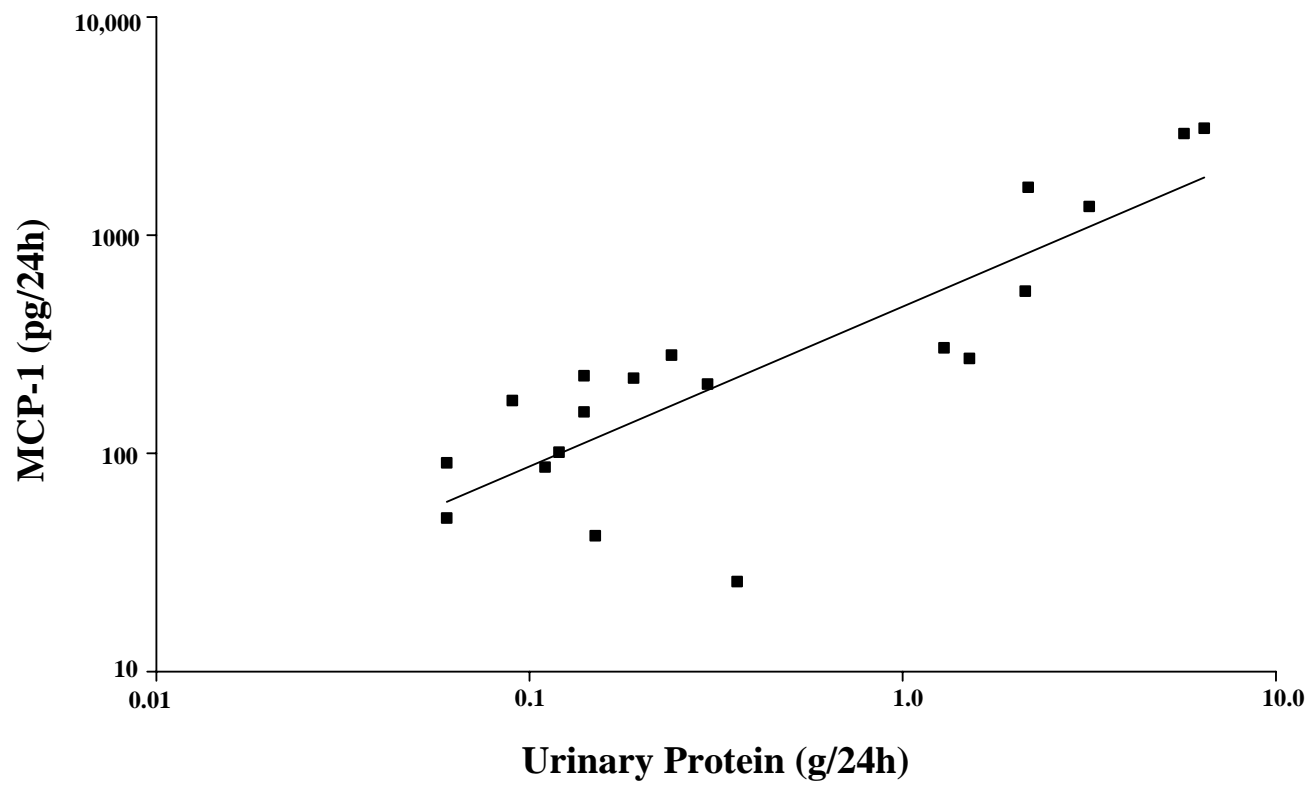

Fig. (2). Correlations between 24-hr proteinuria (UProt) and total urinary MCP-1 activity (log-log plots) in all transplant patients taking angiotensin converting enzyme inhibitors (ACEi) or angiotensin receptor blockers (AngII RB). Data for all ACEi/ AngII RB patients ( $\mathbf{})$ are shown. The regression coefficients are $y=2.67+0.73 x ; r=0.84, p<0.0001$.

of log-log plots of urinary MCP-1 in the transplant patients on ciclosporin-based treatment against urinary protein gave greater values for urinary $\mathrm{MCP}-1$ compared with transplant patients taking tacrolimus or other non-calcineurin inhibitor agents (data not shown). However, patients on ciclosporinbased immunosuppression were the majority of the patients studied (reflecting the predominant calcineurin inhibitor used at the time) and these patients had higher levels of proteinuria compared with the other transplant patients. Indeed, the 9 renal transplant patients with the most severe tubulo-interstitial fibrosis had the highest proteinuria and MCP-1 levels than all other transplant patients (data not shown). 


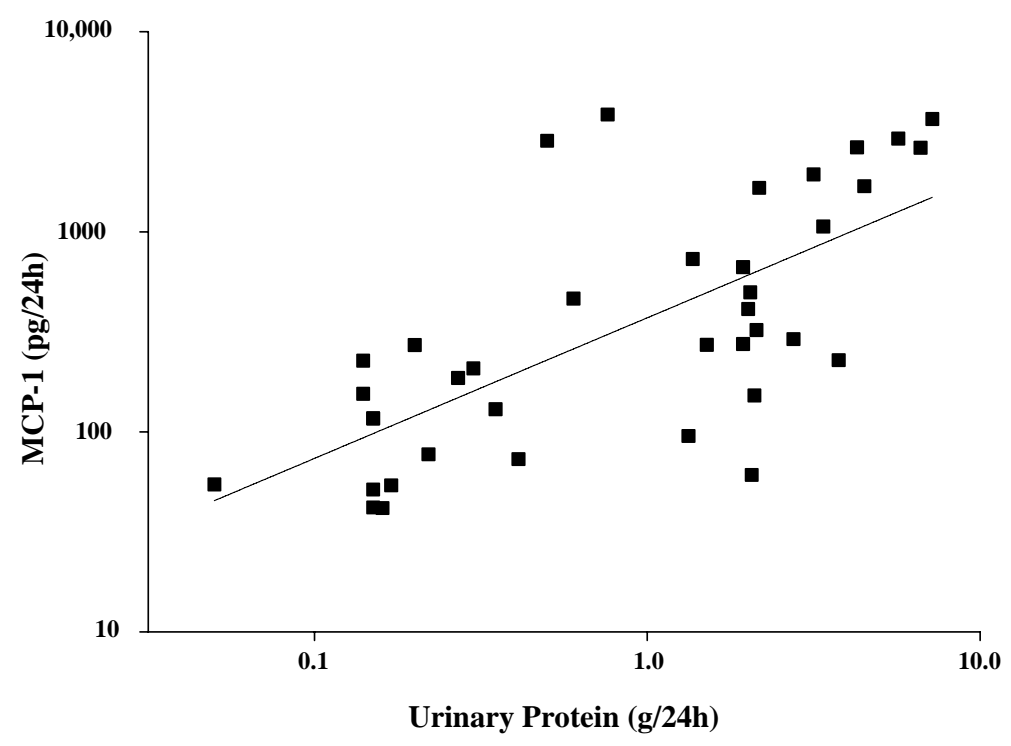

Fig. (3). Correlations between 24-hr proteinuria (UProt) and total urinary MCP-1 activity (log-log plots) in all transplant patients with biopsy-proven chronic allograft nephropathy. Data for all these patients $(\boldsymbol{\square})$ are shown. The regression coefficients are $\mathrm{y}=2.57+0.70 \mathrm{x} ; \mathrm{r}=$ $0.69, \mathrm{p}<0.0001$.

We showed a particularly strong correlation between MCP-1 and proteinuria in the relatively small group of transplant patients taking ACE-i treatment. Use of ACE-i post-transplant has generally tended to increase over the last few years, but not without problems (which can be anticipated and addressed) and particularly in terms of increased metabolic acidosis and hyperkalaemia [7]. There were lower urinary MCP-1 levels in the 12/19 renal transplant recipients taking ACE-i. This might be expected if there was a beneficial effect in terms of a reduction in proteinuria $[4,7,19]$. In the ACE-i-treated group 12 patients with $<0.5 \mathrm{~g}$ proteinuria had MCP-1 levels $<300 \mathrm{pg} / \mathrm{d}$ vs $>300-3000$ in the 7 remaining patients with proteinuria $>1-6.4 \mathrm{~g} / 24 \mathrm{~h}$ and MCP-1 levels increased in parallel with the rise in proteinuria.

A log-log plot of urinary MCP-1 from this study together with our published urinary NAG studies in patients with chronic allograft nephropathy [8] also show a positive correlation between these two parameters (non-transplanted patients $\mathrm{y}=1.093+0.52 \mathrm{x}, \mathrm{r}=0.32, \mathrm{p}<0.01$; transplanted patients $y=0.043+0.873 x, r=0.55, p<0.0001)$ emphasizing the importance of proximal tubular dysfunction in these proteinuric patients.

We did not measure plasma MCP-1. Others have previously shown that there was no significant increase in plasma MCP-1 in patients with kidney disease [13-15] Urinary $\mathrm{MCP}-1$ in proteinuric renal transplant patients reflects a predominant local PTC production promoting increased tubulointerstitial fibrosis. In vitro studies in PTC culture systems and animal models support this view [9-12]. In our study, there was no correlation between MCP-1 and creatinine clearance. This relationship is true providing creatinine clearance is at least $15 \mathrm{ml} / \mathrm{min}$ as in our patients [8, 18]. Additionally, renal function was comparable in all patient groups. MCP-1 levels were unrelated to age (thus allowing comparisons with the volunteers who were younger), transplant duration, mean arterial pressure or blood ciclosporin or tacrolimus levels.
We suggest from the data presented that urinary MCP-1 may represent a useful urinary marker of inflammation, even in proteinuric patients with progressive graft failure.

\section{ACKNOWLEDGEMENT \& CONFLICT OF INTER- EST STATEMENT}

This work was supported by a Grant from Mersey Kidney Research, Liverpool, UK.

No conflict of interest exists for any of the authors.

The authors declare that the results presented in this paper have not been published previously in whole or part, except in abstract format.

\section{REFERENCES}

[1] Nankivell BJ, Borrows RJ, Fung CL, O'Connell PJ, Allen RD, Chapman JR. The natural history of chronic allograft nephropathy. N Engl J Med 2003; 349: 2326-2333.

[2] Williams PS, Fass G, Bone JM. Renal pathology and proteinuria determine progression in untreated mild/moderate chronic renal failure. Q J Med 1988; 67: 343-354.

[3] The GISEN Group (Gruppo Italiano di Studi Epidemiologici in Nefrologia). Randomised placebo-controlled trial of effect of ramipril on decline in glomerular filtration rate and risk of terminal renal failure in proteinuric, non-diabetic nephropathy. Lancet 1997; 349: 1857-1863.

[4] Remuzzi G, Benigni A, Remuzzi A. Mechanisms of progression and regression of renal lesions of chronic nephropathies and diabetes. J Clin Invest 2006; 116: 288-296.

[5] Risdon RA, Sloper JC, De Wardener HE. Relationship between renal function and histological changes found in renal-biopsy specimens from patients with persistent glomerular nephritis. Lancet $1968 ; 2: 363-366$.

[6] Bohle A, Mackensen-Haen S, von Gise H, et al. The consequences of tubulo-interstitial changes for renal function in glomerulopathies. A morphometric and cytological analysis. Pathol Res Pract 1990; 186: 135-144.

[7] Rustom R, Grime JS, Sells RA, et al. Renal tubular peptide catabolism in chronic vascular rejection. Ren Fail 2001; 23: 517-531.

[8] Bone JM, Amara AB, Shenkin A, et al. Calcineurin inhibitors and proximal renal tubular injury in renal transplant patients with prote- 
inuria and chronic allograft nephropathy. Transplantation 2005; 79: 119-122.

[9] Viedt C, Vogel J, Athanasiou T, et al. Monocyte chemoattractant protein-1 induces proliferation and interleukin- 6 production in human smooth muscle cells by differential activation of nuclear factor-kappaB and activator protein-1. Arterioscler Thromb Vasc Biol 2002; 22: 914-20.

[10] K Takaya, D Koya, M Isono. Involvement of ERK pathway in albumin-induced MCP-1 expression in mouse proximal tubular cells. Am J Physiol Renal Physiol 2003; 284: F1037-45.

[11] Wang Y, Chen J, Chen L, Tay YC, Rangan GK, Harris DC. Induction of monocyte chemoattractant protein-1 in proximal tubule cells by urinary protein. J Am Soc Nephrol 1997; 8: 1537-45.

[12] Shimizu H, Maruyama S, Yuzawa Y, et al. Anti-monocyte chemoattractant protein-1 gene therapy attenuates renal injury induced by protein-overload proteinuria. J Am Soc Nephrol 2003; 14: 1496-505.

[13] Rovin BH, Doe N, Tan LC. Monocyte chemoattractant protein-1 levels in patients with glomerular disease. Am J Kidney Dis 1996; 27: 640-646.
[14] Grandaliano G, Gesualdo L, Ranieri E, et al. Monocyte chemotactic peptide-1 expression in acute and chronic human nephritides: a pathogenetic role in interstitial monocytes recruitment. J Am Soc Nephrol 1996; 7: 906-913.

[15] Wada T, Yokoyama H, Su SB, et al. Monitoring urinary levels of monocyte chemotactic and activating factor reflects disease activity of lupus nephritis. Kidney Int 1996; 49: 761-767.

[16] Morii $\mathrm{T}$, Fujita $\mathrm{H}$, Narita $\mathrm{T}$, et al. Association of monocyte chemoattractant protein-1 with renal tubular damage in diabetic nephropathy. J Diabetes Complications 2003; 17: 11-5.

[17] Grandaliano G, Gesualdo L, Ranieri E, et al. Monocyte chemotactic peptide- 1 expression and monocyte infiltration in acute renal transplant rejection. Transplantation 1997; 63: 414-20.

[18] Rustom R, Costigan M, Shenkin A, Bone JM. Proteinuria and renal tubular damage: urinary $\mathrm{N}$-acetyl-beta-D-glucosaminidase and isoenzymes in dissimilar renal disease. Am J Nephrol 1998; 18 : $179-185$.

[19] Shalamanova L, McArdle F, Amara AB, Jackson MJ, Rustom R. Albumin overload induces adaptive responses in human proximal tubular cells through oxidative stress but not via angiotensin II type 1 receptor. Am J Physiol Renal Physiol 2007; 292(6): F1846-57. 